DEPARTAMENTO DE ANATOMIA PATOLOGICA

Diretor: Prof. Dr. Euclydes Onofre Martins

\author{
ADENOMA HIPOFISÁRIO EM BOVINO \\ (HIPOPHISARY ADENOMA IN BOVINE) \\ A. M. SALIBA
Assistente
}

O estudo dos tumores da hipófise apresenta grande importância em consequência da localizaçāo dessa glândula e das importantes funçōes que ela desempenha. Em virtude da presença destas neoplasias observam-se nos animais nāo só fenômenos neurológicos como os de natureza endócrina.

Os fenômenos neurológicos traduzem-se por compressão exercida por êsses tumores sôbre o quiasma ótico, podendo levar o animal até a cegueira, destruição da sela túrcica, compressão do $3 .^{\circ}$ ventrículo e em consequência hidrocefalia interna.

Os fenômenos endócrinos variam conforme a natureza dos ciementos proliferados no tumor. LESBOURYES e col. (1942) fizeram extenso relato bibliográfico da sintomatologia observada em animais com êste tipo de tumor.

Em cães observamos na literatura os casos relatados por BRANDT (1940) e BROUWERS et TSIROYANNIS (1957); em ยqüinos BRANDT (1940) e ERIKSSON e col. (1956); em ovinos CASAROSA (1950); em bovinos MARCATO, ARTIOLI e DI DOMIZIO cit CASAROSA (1950).

Segundo a maioria dos autores, a ocorrència dos tumores hipofisários é bastante rara tanto entre os animais domésticos como no homem. Na literatura nacional não verificamos caso algum de adenoma hipofisário relatado nas diferentes espécies animais.

\title{
OBSERVAÇŌES PESSOAIS
}

O caso que apresentamos é o da hipófise de um bovino proceclente do Matadouro Armour. Infelizmente os antecedentes clínicos do animal possuidor dêste tumor não foram obtidos.

O material a nós enviado para estudo foi registrado no Departamento de Anatomia Patológica sob o número 4328.

EXAME MACROSCÓPICO - A hipófise apresentava-se aumentada de volume, de forma ovóide, media $2,5 \times 2,5 \mathrm{~cm}$.. pesando $10 \mathrm{~g}$ (figs. 1 e 2 ).

$\mathrm{Na}$ superficie externa verificamos pequenas circunvoluçōes e alguns vasos dilatados e cheios de sangue. À superficie de corte 
apresentava, no lobo anterior, formação tumoral que media $2,0 \times 1,5 \mathrm{~cm}$., também de forma ovóide. Esta formaçāo estava circunscrita por uma cápsula de natureza conjuntiva, e possuia aspecto glandular sólido. Notamos, ainda, no interior da massa tumoral, tecido necrosado fàcilmente destacável do restante do tumor.

EXAME MICROSCÓPICO - Fragmentos da hipófise foram fixados em formal a $10 \%$, incluidos em parafina e preparados pelos seguintes métodos: Hematoxilina-eosina, Weigert, F Jot-Wilder, Van Gieson e Mallory (especifico para hipófise)

Nos vários fragmentos examinados verificamos possuir o tumor uma estrutura glandular endócrina tipica, mostrando-se delimitado do tecido hipofisário atrofiado por uma espêssa cápsula de tecido conjuntivo.

O tecido tumoral era formado por cordões celulares anasto mosados, cordōes èstes de 2 ou 3 fileiras de células dispostas ao redor de sinusóides, alguns dilatados e cheios de sangue. Estas células nāo demonstraram polimorfismo nem figuras de mitose, o que indica o crescimento lento do tumor; apresentavam tais cé lulas forma cúbica ou poliédrica, núcleos arredondados ou ovalados e de modo geral um nucléolo e cromatina bastante frouxa; seu citoplasma, desprovido de granulaçōes, exibia uma coloraçāo róseo clara. Evidenciamos, também na massa tumoral algumas células eosinófilas, isto é, células que apresentavam no citoplasma granulaçóes muito finas, de côr avermelhada. Pelo método de Foot-Wilder verificamos delicado retículo.

As células cromófobas são as predominantes neste tumor.

DIAGNÓSTICO: Adenoma cromófobo da hipófise.

\section{DISCUSSĀO}

A sintomatologia observada em animais possuidores dêste tipo de tumor ê bastante diversa. Assim, BRANDT verificou que dois animais possuidores de adenomas cromófobos da hipófise nada apresentavam clinicamente.

A necrópsia êste autor observou apenas calcificação distrófica da musculatura do esqueleto, não afirmando existir relação entre o tumor e estas lesōes. Entretanto, LESBOUYRIES e col. observaram num caso de adenoma cromófobo da hipófise depressāo com permanente astenia, atrofia testicular, alteraçōes na pigmentaçāo, poliúria e polidipsia. À necrópsia evidenciaram adipose generalizada, atrofia muscular e lesōes nas supra-renais que se apresentavam hipertrofiadas. Os exames histológicos revelaram focos de ossificaçāo pulmonar, com osteoblastos no seu interior.

Em relaçāo à idade em que êstes tumores ocorrem parece, segundo pesquisa bibliográfica, ocorrer com maior frequência em animais adultos ou velhos. Estes tumores podem aparecer em raças e sexos diferentes. 


\section{SUMMARY}

The author in this paper studies a case of a cromophobe adenoma of the Hypophisis in bovine.

He comments about the rarity of these tumours not only in human but also in Veterinary medicine, and its consequences. He also studies the macroscopic and microscopic aspects and considers that this tumour is probably the first ever found in Brazilian literature.

\section{BIBLIOGRAFIA}

BRANDT, A. J - 1940 - Uber Hypophysenadenome bei Hund und Pferd Medd. Veterinärhogsk. Stockh., 14

BROUWERS, J. - TSIROYANNIS, E …1957 - A propos d'un cas d'adénome hypophysaire à cellules chromophobes chez le chien. Ann. Méd. Vét. 101 (3): 197-209

CASAROSA, L - 1950 - Adenoma eosinofilo dell'anteipofisi in pecora (ovis aires). Ann. Fac. Med. Vet. Pisa, 3: 13-26

ERIKSSON, K. - DYRENDAHL, S. - GRIMFELT, D. - 1956 - A case of hirsutism in connection with hypophyseal tumour in a horse. Nord Vet. Med., 8 (10): 807-814

LESBOUYRIES, G. - DRIEUX, H. - CHARTON, A - MACHARKA, K. 1942 - Adénome chromophobe de l'hypophyses et syndrome pluri. glandulaire chez un chien. Bull. Acad. Vet. Fr, 15: 298-317 


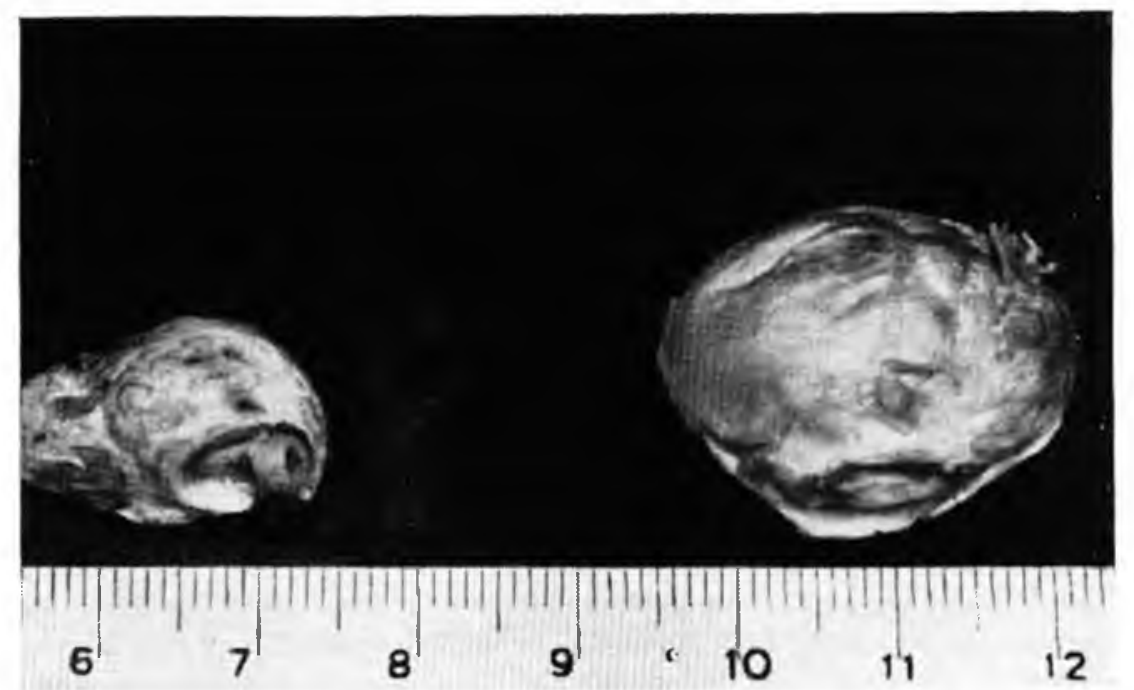

FIG 1 - Aspecto macroscópico da nupofise de bovino normal e da hipofist tumoral

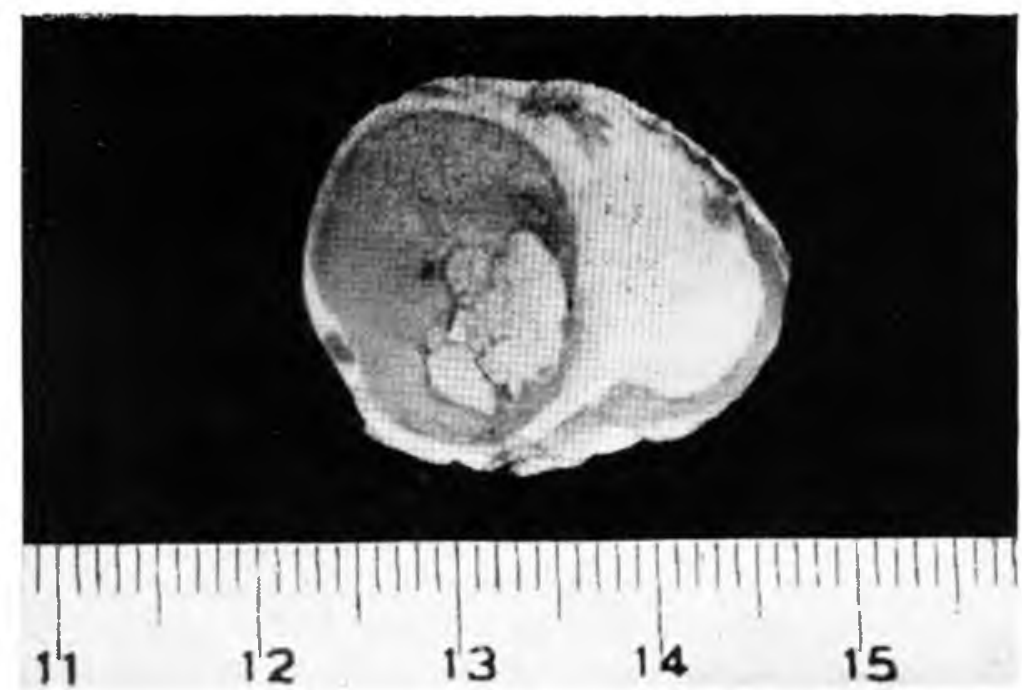

FIG. 2 Aspecto do tumor 


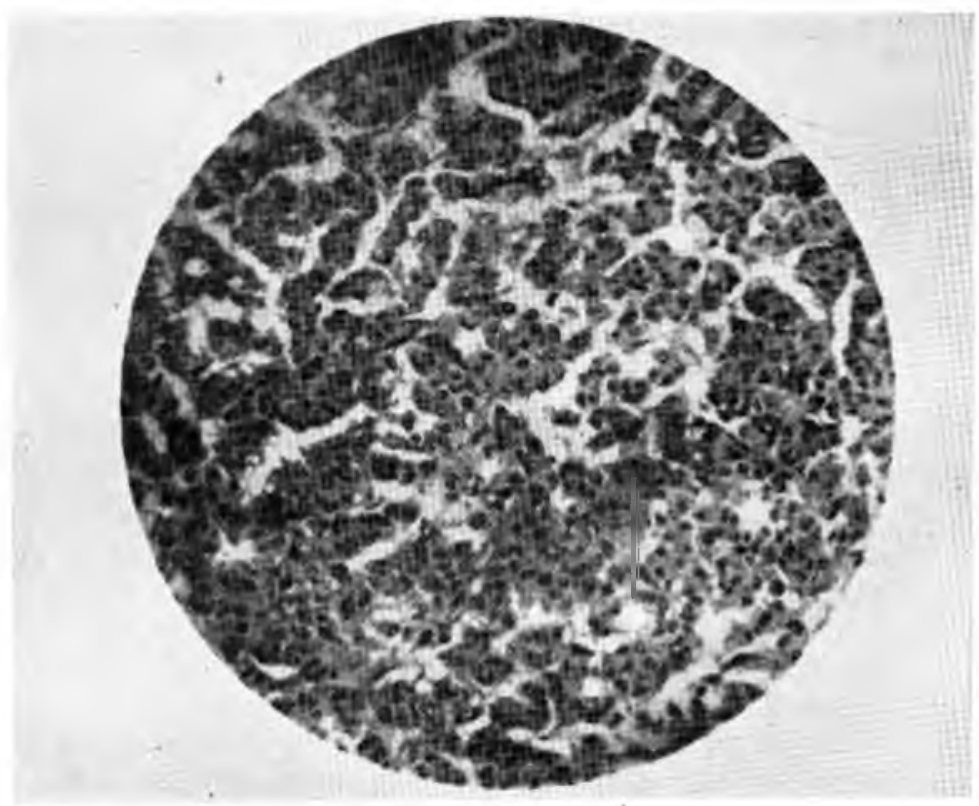

FIG 3 - Aspecto histologico do tumur (In) $x$ col. H. E

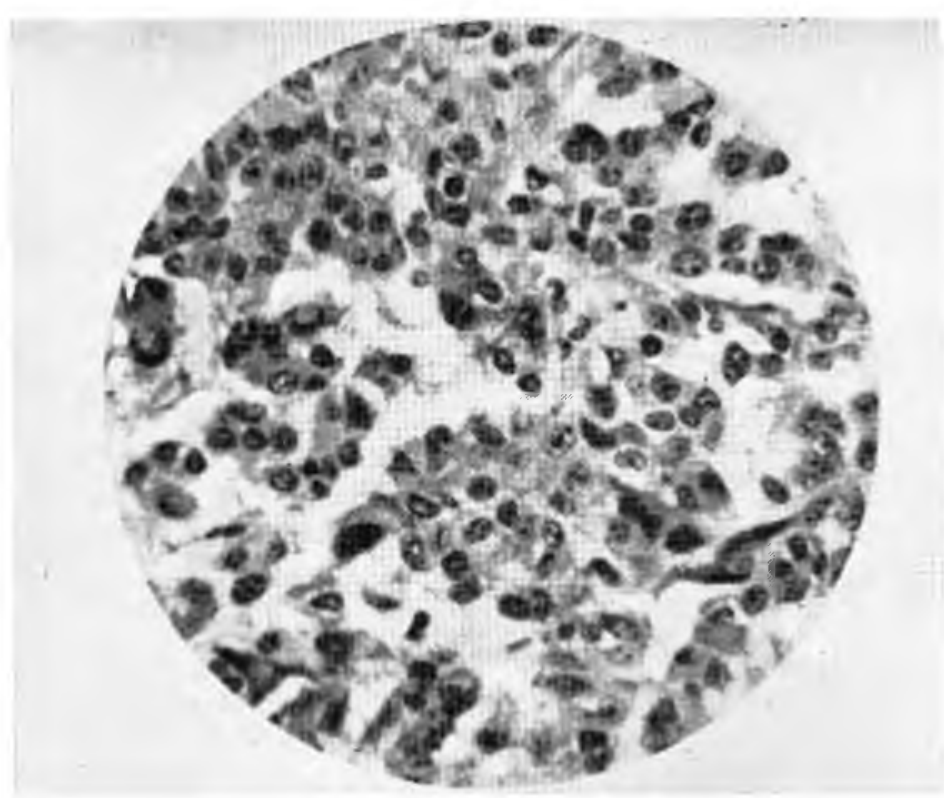

PIG 4 - Detalhe da fotografia anterior $250 \times \mathrm{col}$ II $\mathrm{E}$ 